\title{
HUERFANÍA, HUACHISMO E INFANCIA EN LA POESÍA DE DELIA DOMÍNGUEZ
}

Orphanhood, bastardy (huachismo) and childhood in Delia Dominguez's poetry

Claudio Guerrero*

Resumen

En este artículo se estudia la representación de la infancia en la poesía de Delia Domínguez, la que se expresa como una estética de la orfandad y el huachismo que intentan restituir un estado primigenio, embrionario, mediante un constante mirar para atrás con ojos de niña, en el contexto de una comunidad poetizada que da lugar al encuentro regresivo e imposible de la madre con la hija. En esta búsqueda, la infancia cumple un rol reunificador y reparador.

Palabras clave: Huerfanía, Huachismo, Infancia, Comunidad.

\section{Abstract}

In this article, the representation of childhood in Delia Domínguez's poetry is analyzed. This is expressed as an aesthetics of orfhanhood and bastardy (huachismo) that tries to return to an original, embryonic condition, by means of a constant looking back through a girl's eyes, in the context of a poeticized community that gives way to the regressive and impossible meeting of a mother and her daughter. In this search, childhood fulfills a reunifying and repairing role.

Key words: Orphanhood, bartardy (Huachismo), Childhood, Community.

\section{RECEPCIÓN CRÍTICA}

La trayectoria poética de Delia Domínguez (1931) cuenta con escasos estudios existentes en torno a su obra. Por ser mujer o por otra cosa, lo cierto es que su poesía se ha mantenido durante años bajo un opresivo silenciamiento. Dentro de este mínimo corpus son menos frecuentes aún las explicitaciones en torno al tema de la infancia. Campaña (1982) señala que la infancia forma parte del proyecto de la poesía de Domínguez de vivir enraizada, en tanto signo de pertenencia y participación dentro del medio en el cual le ha tocado nacer y desarrollarse. Poesía que constituye una "larga plegaria" llena de rupturas, rebeldías y preocupaciones por la suerte del ser (162). Dentro de este proyecto, la infancia vendría a constituirse, entonces, como un paso obligado para el reconocimiento de los orígenes dentro de un determinado contexto cultural.

El largo silencio posterior de la crítica pareciera concluir cuando nos encontramos con uno de los primeros estudios sistemáticos de la obra de Domínguez. Concordamos con algunas de las características que Cuneo (2004) señala son propias de esta poética. Por una parte, la recurrencia a una memoria fetal y ancestral. Por otra, la relación de madre-hija que establece con la tierra (7). Ambas características se 


\section{Claudio Guerrero}

manifiestan de modo sui generis en esta autora. Respecto de la primera, Cuneo señala que es consecuencia de determinadas reminiscencias de infancia, "de sus descendientes y de toda la historia del hombre sobre la tierra" (11), de modo que el poema se vive como herencia de un pasado que es necesario rescatar o revitalizar. Respecto a la segunda, la autora lo relaciona con una actitud de hacer a la tierra, siendo la poeta la rescatadora de esos "parlamentos" que conservan las cosas mismas, no las imágenes de las cosas. Debido a esta constante presencia de lo real, en donde la biografía no queda de lado, dice Cuneo, que esta poesía es "impura e hiperrealista" (23), en donde la vida, como suele ocurrir en el campo, se muestra tal cual es, descarnada, sin grandes metáforas.

El pasado al cual alude la poesía de Domínguez, a decir de Mansilla (2004), se relaciona con el hibridismo cultural del sur de Chile, específicamente la zona donde nació la poeta (Osorno), marcado por una triple vertiente: el colonialismo germano, las costumbres indígenas (mapuche-huilliche) y el catolicismo hispano (65). Se trataría, por tanto, de un pasado ligado directamente a su experiencia de vida inmediata, por más que quiera hacerla extensiva en algunos poemarios de tono nerudiano, como veremos, a toda la historia del ser humano. En esta poesía, por sobre todo, se remarca y se intenta diferenciar una experiencia de vida rural y no urbana, de manera coral: "múltiples voces aglutinadas" — señala Mansilla_- producto de "la necesidad de atestiguar la misa del universo" (57). Pero otra característica de esta poesía que nos parece importante rescatar aquí es aquella otra que apunta Mansilla: la idea de que regresar al pasado es un "desnacer": "Es como si al nacer, por el hecho mismo de comenzar a ser cuerpo mortal, se clausurara una posibilidad de ser en plenitud, por sobre las limitaciones de la materia, de la temporalidad y de la muerte" (61). Por eso esta poesía vendría a ser una escritura que transita entre el ser y el no ser, entre el nacer y el morir, en un amasijo o revoltura de memorias, sueños y vivencias (62). Migrancia misteriosa por la gran casa mestiza de América del Sur, agrega Mansilla en otro estudio (Mansilla, 2009:44), que trata de unir el presente con el origen por medio de un largo diario de viaje. Poesía documental cuyos referentes son signos revueltos, al mezclar imbricadamente experiencia individual y colectiva. Volveremos más adelante sobre estas ideas.

Delia Domínguez, en su "Discurso de incorporación a la Academia Chilena de la Lengua" (1992), expresa su particular visión que tiene de la infancia. Sin pretender usar esto como parte de nuestra argumentación, lo planteamos acá para señalar que este tema forma parte de su plan de escritura, por consiguiente, ocupa un lugar especial. Dice la autora:

Desde el fin del mundo podría volver con los ojos vendados a mi vieja casa en las colinas. Pero ese paso de vals no sería, no es, para resucitar paraísos de infancia o para aliviar dolores de parto y ponerme a la segura en ese reino — paralelo 40 sur- donde la poesía es mi leche de madre, no. Porque el prendimiento a la zona con la tira del ombligo sangrando todavía, es una razón de vida y una razón de muerte: mi forma de salvación eterna (123). 
Como vemos, para la autora la infancia no es un espacio paradisíaco ni cobijante. La infancia es, todavía, un lugar sangrante, herido como el ombligo del niño recién nacido. Un lugar frágil, donde la vida y la muerte luchan entre sí. Un lugar que, en su contradicción permanente, resulta ser una manera y una razón de vivir y escribir poesía. Veremos que esta infancia se despliega a lo largo de toda su poesía de modo complejo, alcanzando aristas novedosas y sugerentes.

\section{UNA INFANCIA POR (RE)NACER}

Haciendo una revisión de toda la poesía de Delia Domínguez, es posible señalar que existe en ella una especial recurrencia a la primera infancia como motivo de representación y, en especial, a la maternidad desde el periodo de gestación hasta el alumbramiento. Como señala Guerra (1994) no ha existido en la cultura occidental un discurso propio de la mujer para modelizar su experiencia biomaterna: "Como si el embarazo y el parto hubieran ocurrido siempre en una cámara oscura, hasta ahora, permanecen en el ámbito de lo que no posee lenguaje" (164). Creemos que Domínguez instaura en su poesía, quizás como solo Gabriela Mistral lo había desarrollado hasta entonces, una poética que nombra y representa estas realidades, pero de un modo renovado y particularísimo.

En efecto, esta poética se muestra principalmente desde la constante alusión a la experiencia de dar a luz y la lactancia, con frecuentes repercusiones isotópicas a palabras como nacimiento, ombligo, cordón, pecho, leche, fijando en esta instancia el anhelo de querer volver a un origen embrionario para rescatar desde allí lo más puro y genuino del ser. Las alusiones son visibles en cada una de sus producciones poéticas. Siguiendo un orden cronológico de publicación, intentaremos aquí articular las principales características de esta infancia representada.

La representación de la primera infancia es posible percibirla ya a partir de su segunda producción, La tierra nace al canto (1958), libro de tono románticamente elegíaco. En el poema "La luz definitiva", por ejemplo, la hablante lírica se lamenta de la pérdida de su objeto de amor. Sin embargo, este permanece de modo definitivo en la frágil y profunda raíz de su ser: "te siento vigoroso amamantando / en la frágil raíz de mi existencia" (63). Esta fragilidad de la existencia hace que la hablante lírica se refugie en la promesa de un trabajo lírico con las palabras, en la posibilidad de entablar un oficio con ellas y con esto reafirmarse como un sujeto con un sentido. En el poema "Me llamo" establece su propósito. Y eso significa llegar a su origen como poeta y como mujer poeta:

\footnotetext{
Ahora abrir el pecho y estrellarse, sacar a luz los años contenidos, repartirse en un grito, buscar, cavar profundo,
} 


\section{Claudio Guerrero}

volver a enmudecer bajo la tierra,

hasta el embrión primero preguntarse

y luego este comienzo en rebeldía

crujiendo alucinado entre la sangre (67).

Se establece aquí, entonces, las bases de una búsqueda poética, un querer volver a enmudecer (recordemos la etimología de la palabra infante: el que no puede hablar) y aún más, un querer verse dentro del útero para encontrarse en ese embrión que aún no nace. Una autoconvocatoria a indagar hasta lo más profundo de su ser, hasta su infancia aún por gestarse, en una suerte de viaje a la semilla carpenteriano en el sentido de un desplazamiento y regresión temporal hacia un origen, ${ }^{1}$ para configurarse como persona con un objeto de vida y así luego "aprenda a ser poeta" (67). En su proyecto, entonces, la infancia ocupa un lugar central como lo confirma en el poema "Escribo a puerta abierta": "por una hendija azul recupera tu infancia / y cántala todavía, / en pleno arrojo, a puerta abierta" (71). Una infancia nonata, aún por acontecer, que promete llegar junto con las palabras.

Esa infancia que pretende resurgir desde su estado embrionario es, justamente, lo que el lector encuentra en las producciones posteriores de esta poeta y de manera ampliada y complejizada. En su siguiente libro Obertura siglo XX (1961), con clara influencia del Neruda americanista, la infancia aparece en un contexto de política identitaria de búsqueda de lo esencial americano en lo terrestre y campesino. Es así como surge "Presencia del hombre puro", un poema donde el hombre continental es descrito desde el vigor de sus oficios con los elementos y herramientas básicos. Pero este hombre viril y fuerte, como es descrito, también tuvo un origen: fue embrionario "gestándote, terrible y poderoso en tu silencio" (2) y fue bebé:

Vienes con tu secreta astrología
pegado a este pezón terrestre
mamando huracanado
la leche virgen y olorosa
de las vacas recién paridas
y te conocen todos los caminos
hombre triste y alegre
con niñez de fruta, de contentamiento simple. (1)

Ese infante americano - silencioso, mudo- luego es representado más crecido, ahora como niño, en el poema "El niño pueblo canta", con el nombre de Víctor Tejeda: "hijo del pueblo pobre de mi tierra, / doce crepúsculos apenas tiñeron tu miseria / _

\footnotetext{
${ }^{1}$ Nos referimos al relato original del cubano Alejo Carpentier (1904-1980), "Viaje a la semilla" (1944), desde el momento mori de un hacendado, que retrocede vertiginosamente en su vida hasta llegar a la niñez, la pérdida del lenguaje y su gestación en el útero materno, al mismo tiempo que todos los elementos de su casa vuelven a su punto original y se disuelven.
} 
niño azul de tristezas - " (9). Este niño ha nacido "en la propia entraña de la sonata agraria" y pese a ser un "pétalo proletario de las piedras / acribillado y duro" es erigido por la hablante como "la fina luz creciente / que empuña los notros colorados / de mi patria" (10). ${ }^{2}$ Sin embargo, dice, estará "tan solo", tan "furiosamente solo" (10) como ella, que serán compañeros, porque "tú y yo nos sabemos / de dulcísima luz configurados, / de humana y suave greda" (11). Sobre esto último nos interesa detenernos, porque da cuenta de manera ficcionalizada de una situación estudiada por antropólogos e historiadores de nuestro país, Montecino (2004) y Salazar (1990) principalmente, y que tiene su raíz en el problema de la ausencia del padre. Nos referimos al concepto de huacho, extensible a toda la condición identitaria latinoamericana, concepto que podemos estudiar desde una perspectiva tanto biológica como histórico-antropológica y en su conversión y uso metafórico-literario.

Esta voz de origen quechua deriva de huachuy: cometer adulterio, y de huajcha: extraño, pobre, miserable. De ahí que ya en quechua debe haber existido esta palabra para denominar al huérfano (Lenz, 359-361). Lenz, además, recoge nueve posibles acepciones para el término, siete de las cuales aluden a una idea de huerfanía y abandono: 1. Hijo ilegítimo. 2. Niño huérfano. 3. Animal nuevo separado de la madre criado en la casa. 4. Planta de cultivo que crece en alguna parte donde no se ha sembrado intencionalmente. 5. Huevo de avestruz encontrado lejos de su nido. 7. Objeto solo, sin su par. 9. Aguardiente malo o débil.

El término huacho, entonces, se hace patente desde su negatividad subyacente, pero también en conjunto con su carácter silvestre. De hecho, uno de los derivados de la palabra, ahuachar, significa domesticar, amansar y otro, acercarse, arrimarse. Como animalillo salvaje, el niño huacho americano ha crecido a la deriva, fortalecido en su abandono, gracias a la madre que lo cobija, lo ahuacha, a-huacha, quitándole su condición de abandono, siendo su padre-madre a la vez. La hablante de este poema, que se llama a sí misma como "mujer del Sur", acoge a este huacho como si fuera su madre y juntos se erigen como núcleo familiar, pasando a ser el muchacho, prontamente, ya no un niño, sino un hombre, pero sin ese referente masculino necesario para su crecimiento y formación. Este movimiento opera en la mujer, en muchos casos, como desplazamiento de su objeto amoroso, del hombre al hijo, haciendo que su cuerpo se prepare no para recibir a un hombre, sino a un niño. Porque, como señala (Montecino, 61), la mujer también es huacha, también es solitaria: ella, por fuga o muerte de su pareja, también sufre el abandono. Esta mujer, que ha desplazado su afecto junto a los hijos desvalidos por la ausencia del padre (o de ambos), forma parte de un tópico insistente en la cultura americana: la experiencia del abandono y lo que podríamos denominar en literatura la "estética del huachismo",

\footnotetext{
${ }^{2}$ El notro es originario de Chile. De acuerdo con la DRAE, viene del mapuche notru, que significa ciruelillo. Se trata de un árbol de hojas oblongas de un color rojo vivo y cuya madera se utiliza para obras de ornato.
} 


\section{Claudio Guerrero}

que se aplicaría a la trayectoria del niño/a en tanto sujeto pasivo del devenir de los acontecimientos que lo deja, literalmente, abandonado a su suerte.

El huachismo es, en gran medida, un padecimiento y solo en algunos casos una "opción de dignidad" (Salazar, 26). En el caso de la poesía de Domínguez, hay tránsito que va de la huerfanía al huachismo, puesto que la orfandad (biográficamente instaurada por la muerte de la madre a los cinco años) se vive como huachismo. En efecto, la hablante de sus poemas, como lo familiar está roto y su origen ha sido nebulizado por la falta de memoria y vivencias de experiencias maternales, busca incesantemente la pertenencia a una comunidad reducida, local, en tanto posibilidad de instaurar una matriarcalidad postiza. Se trata de un huachismo existencial producto de la carencia y el borramiento de la madre, en una acusación soterrada de abandono que prontamente busca ser reparado. Esto genera el anhelo de su encuentro con la madre y un ansia de ser madre, también, de modo de poder sustituir la falta. De este modo, se vive una cierta marginalidad de la niñez por ausencia que busca en el tronco familiar un refugio sagrado para esta comunidad dispersa de la cual forma parte y que está conformada por otros huérfanos y huachos. En este punto, entonces, huerfanía y huachismo se entroncan y amalgaman en un encuentro en donde la segunda es posibilidad reparatoria de la primera: opción de dignidad.

\section{EN BUSCA DE LA MADRE AUSENTE}

El motivo de los niños solos y desprotegidos es recurrente dentro de la obra de Domínguez. En otro poema de Obertura Siglo XX, llamado "Presentimiento universal de cada día", la hablante alude a los niños en situación de calle ${ }^{3}$ que viven junto al río que cruza la gran ciudad: "la noche va a acostarse en las acequias/ los niños dormirán en las acequias / la muerte dará a luz en las acequias" (35). El "pequeño cadáver" (35) queda resonando dentro de sí, arañándole la voz, llorando dentro de su corazón. Se trata de una infancia "errante, transcurrida / en la costumbre de los cementerios" (41), como señala en otro poema, una infancia signada por la muerte, una infancia de "suave niña olvidada" (49), de "niños sonoramente asesinados / en las catacumbas del mal" (60). Niños y niñas que, sin ser adultos, andan "destetados llorando" (49) por la vida, precisamente por esa marca inicial de pérdida y orfandad acentuada cuando la infancia "se nos despedaza" y "comenzamos a vivir o a morir" (54), es decir, en la ambigüedad de una vida que no se sabe si es para vivirla o para considerarla como una degradante progresión hacia la muerte.

Ese despedazamiento, abandono o padecimiento es equivalente en esta poesía al momento del nacimiento, cuando el feto es sacado del vientre de la madre. Aquello que era, figuradamente, un solo cuerpo, uno dentro del otro, ahora son dos pedazos de

\footnotetext{
${ }^{3}$ El drama de los niños y niñas de las caletas del Mapocho sigue siendo un tema vigente. Fue a mediados del siglo XX, sin embargo, cuando el debate social se acrecentó debido a su masificación. La fundación del Hogar de Cristo en 1944 y de instituciones estatales de apoyo al abandono del niño/a han podido corregir, en parte, esta imagen recurrente de las riberas del río que cruza la capital de Chile.
} 
cuerpo: "la consagración del hombre ante la nada" (56). Esto permite afirmar a la hablante que el ser humano, desde su niñez, es un sobreviviente en "el cantoral del tiempo" (60), en "el cancionero trágico del siglo" (69). Cantoral, en sentido religioso; cancionero, en clave de música popular. En uno u otro caso, el efecto es el mismo: la idea de un tiempo coral marcado por melodías tristes. Sin embargo, este niño que es capaz de sobrevivir a todas las fuerzas contrarias de la muerte, es un niño que termina siendo "Luz definitiva", un "pagano endurecido" (69), dignificado. Es, desde su origen, un "embrión divinizado" (68), porque trae consigo la esperanza del hombre. Aquel despedazamiento que no se sabía si tenía una connotación positiva o negativa, termina siendo, finalmente, consagrado, elevado, precisamente por ser promesa de vida en medio de la muerte. Comenzamos a vivir, como sobrevivientes de una muerte: la sacada del útero. En este "retroceso", el ser humano pareciera encontrar su esencia de semilla fundadora de vida. Lo paradójico resulta en que para salir al mundo debe abandonar su estado placentario - placentero- para vivir el coro dramático del presente temporal, como lo reafirmamos a continuación.

Ya señalamos al comienzo que una de las tematizaciones de la infancia que se imponen en esta poesía tiene que ver con un estado embrionario anhelado. Búsqueda que esconde, a su vez, las ansias por un encuentro con la madre ausente. Por esto, parece acertado rescatar aquí algunas ideas relacionadas con la maternidad y con el rol que juega la placenta en la construcción de la relación madre-hijo, de acuerdo con el desarrollo propuesto por la bióloga del Liceo Colbert de París, Hélène Rouch, entrevistada por Luce Irigaray (1992). Rouch señala que el niño es diferente de la madre a partir de la construcción de la placenta durante el periodo de embarazo, a diferencia de lo planteado tradicionalmente por el psicoanálisis. Este señala que existe una fusión imaginaria entre madre e hijo por el proceso de maduración del feto hasta su nacimiento y luego por su total dependencia durante la lactancia y sus primeros años. Fusión que luego es imprescindible romper para que el niño se convierta en sujeto, en lo que se ha denominado el estadio del espejo, cuando el niño es capaz de reconocerse como una entidad separada de su madre, entrando al mundo simbólico por medio de la adquisición del lenguaje. La quiebra de esa fusión es facilitada por un tercero — padre, ley, Nombre del Padre, etc.—, quien evitaría que esta fusión acabara en la psicosis, ayudando a establecer un orden.

Sin embargo, señala Rouch, que este tercero no hace más que reiterar y remarcar, a otro nivel, una separación que ya existe durante la preñez gracias a la placenta y, en el instante del nacimiento, a la salida de la cavidad uterina y que no debe forzosamente relacionarse con lo que propone el imaginario cultural: pérdida del paraíso, expulsión o exclusión traumatizante, etc., al ser entendidas como los únicos modos de concebir el advenimiento del lenguaje (40). "La placenta es un órgano del niño que se ha desarrollado gracias al cuerpo de la madre" (41). Es una donación de la madre hacia su hijo, pero es algo que le pertenece a él. Existe entre ambos, entonces, una separación que es al mismo tiempo una unión. 


\section{Claudio Guerrero}

Esta separación que es al mismo tiempo una unión es fruto de una negociación entre el sí de la madre y el otro, el embrión. La madre reconoce a ese otro extraño dentro de su cuerpo y por ello fabrica los factores placentarios necesarios para su supervivencia. La placenta es un tejido, "formado por el embrión, imbricado estrecha y totalmente en la mucosa uterina, y que, aun así, se mantiene independiente" (36). La placenta juega un papel mediador en un doble plano:

Por una parte, es el espacio que media entre la madre y el feto, lo que significa que los tejidos maternos y los tejidos embrionarios nunca llegan a fundirse. Por otra, constituye un sistema regulador de los intercambios entre ambos organismos que no se contenta con organizar cuantitativamente esos intercambios (sustancias nutritivas de la madre hacia el feto, residuos en sentido inverso), sino que modifica el metabolismo de la madre; transforma, apila y redistribuye a la vez los materiales maternos para ella misma y para el feto (36).

Así, la relación posibilita que el feto crezca sin agotar a la madre. Por consiguiente, la relativa autonomía de la placenta no puede reducirse a la teoría de la fusión como tampoco a la teoría de la agresión (parásito o cuerpo extraño), concluye Rouch.

En la poesía de Domínguez es posible rastrear este momento embrionario como un estado placentero ${ }^{4}$ del sujeto aún por nacer en comunión con la madre, pero ya diferenciado: ni fusión ni parásito, sino diferente, pero juntos, en una relación que ya había anotado Mistral en uno de sus poemas, titulado "Canción de la sangre": "Duerme, mi sangre única (...) / fanal que alumbra y me alumbra / con mi propia sangre" (Mistral 1924 65). Es decir, una relación que es tanto fundación de una nueva vida, pero también refundación para la mujer que da a luz, quien es alumbrada por el recién nacido, pese a que ambos conservan la misma sangre. En este sentido, el nacimiento vendría a ser una separación traumática - un "desnacer"- que prontamente se diluye al ser la mujer "alumbrada" también. En ella queda la marca o huella, una cicatriz, de una nueva vida. La nostalgia ficcionalizada de esa comunión por la placenta mediante una memoria fetal que traza regresivamente el camino del nacer, resulta ser una característica única, poderosa y singular de esta poesía.

\section{EN BUSCA DE UNA COMUNIDAD DE AMOR}

El poemario titulado Parlamentos del hombre claro (1963) es uno de los libros de Delia Domínguez casi enteramente dedicado a la infancia y en donde se retoman y profundizan algunos de los temas que había tratado hasta entonces. Ahora, sin embargo, el contexto es netamente rural, local, en donde la oralidad tiene un valor especial. De ahí el parlamentar como sinónimo de hablar, charlar. Pero también en este poemario se reafirma la idea de volver a lo embrionario, a lo más puro del ser humano, pese al signo, huella o marca que deja la experiencia de la muerte de la

\footnotetext{
${ }^{4}$ Nótese la aproximación semántica a placentario. 
madre en el huacho, el niño de padre desconocido o ausente, ahora enteramente huérfano. La hablante de estos poemas una vez más asume el rol de madre sustituta que ahuacha. En el breve prefacio que inaugura el libro, queda en claro esta situación:

Un día de invierno en la zona, una mujer dio a luz con las caderas llenas de lluvia. Los primeros respiros se confundieron con el balido de los corderos asustados. No había arcoíris ni silencio para la mirada muerta de la madre, mientras a campo raso, los caminos de tierra empozados, dejaban pasar la vida — como es allácon la inacabable percusión del viento.

Después el tiempo levantado al hombro sin cobijo posible, y siempre el clima duro sollozando de Este a Oeste en los graznidos de los patos salvajes. Entonces, desde alguna parte vino el canto a ocuparse del hijo para que no estuviera solo, y nacieron estos parlamentos en necesidad de su ternura, o de una simple comunicación con sus hermanos (9).

El libro abre con el poema "La creencia", dedicado a Benjamín Subercaseux, escritor chileno, autor de la novela y en donde expone su teoría de la existencia de dos tipos de infantes: los niños de sol y los niños de lluvia. Los primeros son alegres y desbordantes, luminosos y entusiastas. Los segundos, en cambio, son apagados y oscuros, introvertidos, preocupados. Ambos tipos, en resumen, dan cuenta de una binaria manera de entender la compleja psicología de los niños. La hablante, sin embargo, no se preocupa mayormente de esta distinción, sino que más bien de la oposición niño/adulto.

En efecto, en este poema de tono confesional y escrito con un tiempo verbal imperfectivo, la hablante recuerda cuando "era fundamental creer en la palabra de los mayores" (13). Eso daba seguridad y hacía que los niños sonrieran confiados en la cocina. Pero también recuerda el golpe inicial de la madre muerta, apelando a la propia biografía: "De niña hube de cantar y creer / para no derrumbarme / detrás del funeral de nuestra madre / cuando quedamos fijos con mi hermano / arrimados a un tronco de cerezo" (14). Esta huerfanía marcadora de su infancia permite reafirmar su creencia de una poética capaz de restablecer y exaltar las cosas que permiten cubrir ese vacío, aquellas que permitieron la sobrevivencia y que fue aprendido de los mayores, especialmente de su padre, aquel cuyas manos "me forman una pequeña gruta dulce / con sus dos muros fieles" (20): gruta dulce en donde recae y se guarda la ternura, la esperanza, el compañerismo, la tenacidad del trabajo cotidiano y un espacio de peregrinación y recuerdo permanentes de la madre muerta.

La madre se constituye en esta poesía como un referente habitual de los deseos y anhelos embrionarios de la hablante. En el poema "La madre", precisamente, se escenifica y representa el momento del nacimiento primero con un tono que advierte de sus peligros y luego con un tono de profundo agradecimiento: 


\section{Claudio Guerrero}

De pronto los párpados no obedecen a la luz.

Una tiniebla pegajosa me hacía sudar las sienes

$\mathrm{y}$ alguien

estiraba mis brazos para desgancharlos

desde afuera, mientras un puño oscuro

me anudaba los ojos.

Una fina hoja de sable

discurría entre el aliento y la muerte.

Pero tu mano, madre, tu mano

con la leche y la lluvia de astillas vegetales,

la vasta humanidad de tus cortezas

por mi heredad sonora, cruje,

y marcó con tu voz la vieja casa

de simple envigadura

donde implantaste mi primaria forma

de mujer campesina (23).

Esa fina hoja de sable que discurre entre el aliento y la muerte bien puede ser la imagen del peligro intrínseco a todo nacimiento: el despojo de la vida del recién nacido arrojado, de pronto, a unas condiciones atmosféricas absolutamente diferentes a las que encontraba en la placenta. Al mismo tiempo, puede simbolizar la tijera que separa, definitivamente, al menos de manera física, la unión de la madre con su hijo. Sea como sea, es esa madre la que luego, con su mano cariñosa, su leche y su "heredad" marca los designios de la niña que se autodenomina, ya adulta, como mujer campesina.

Sin embargo, pronta y trágicamente, esa misma madre de la cual la hablante se muestra agradecida fue después "una dulce niña muerta entre mis manos" (24) permaneciendo "en la mandíbula de la juventud, o / en la lágrima de los niños solos / amamantados de lobas en asilos turbios" (24). La hablante luego esboza algo de la causa de muerte de su madre, a quien tilda de "mi niña criolla" (25): "Yo sorbí de tus pechos / el ajenjo vital de la amargura, cuando / un veneno hipócrita destilaba su oro / pulmón adentro, y te silenciabas sin misericordia / para crecerme" (25), para luego convertirla en la madre de todos los hijos de la tierra, haciéndola universal y de esta manera estar presente, viva.

En esta escenificación de la relación madre-hija se produce una suerte de inversión de roles: la madre pasa a ser una niña y la niña, rápidamente, una mujer. Ambas terminan formando una "Matria": un espacio poético de figuras femeninas que intercambian roles y que se configuran en el mundo ocupando un espacio diferenciador, siguiendo la misma lógica de imbricaciones a manera de hilachas que se reúnen, característica de su poesía. En el caso de la hablante predominante de esta poesía, se trata de un espacio marginal de poeta, mujer y campesina, en el borde de los centros masculinos de poder simbólico. Espacio, sin embargo, que se propone ampliar al incorporar otros elementos de la realidad que son atingentes al universo 
poético que se intenta construir y que es equivalente a una comunidad: un espacio pequeño, pero fraterno; cercano, amigable, retributivo, ahuachador.

Es por este anhelo de formar una comunidad que el entorno de vida inmediato que la hablante recrea es el campo, el lugar escogido para el cultivo de ideales que parecieran no representar ya las grandes urbes. Este es uno de los elementos que dan vida y color local a la "Matria". Por tanto, allí se escenifica la mayoría de sus experiencias y representaciones. De hecho, el lenguaje que predomina en sus versos es uno que nombra las cosas propias de este espacio (tierra-terrestre son palabras constantes en toda su poesía, a lo cual podríamos agregar todos aquellos que se aproximan semánticamente, por ejemplo: huerto, brote, notro, maíz, gallina, huevos, corteza, vacas, etc.) evidenciando de esta manera su profunda "visión telúrica" (Cuneo, 2000:43). Así, no extraña que lo más puro del ser humano que se rescata a través del niño se asocie a la vida de la provincia, a la experiencia de la ruralidad. A partir de ese espacio se muestra a un niño acogido, dulce y sano, alegre y bueno. Así, el niño de la provincia es de "tono de agua limpia" (39), es un niño entendido "en aguas y granizos" (41), un niño prístino como el agua crecido bajo la lluvia constante del sur, un niño de "casta belleza" (42). Se trata de una visión idealizada de una infancia no contaminada por la modernidad de la urbe, en el contexto del pueblo rural entendido como una gran comunidad. Por eso, allí, "todos responden" (45), se cree en la familia y en el valor generoso de la tierra, las personas son buenas y agradecidas como el niño que "bendice los amaneceres / cargando el silabario entre la escarcha" (45), y se apoyan entre sí, por lo que es posible "ayudar a sentir a la comadre Rosa / en sus velorios de angelito" (46). Recordemos que los velorios de angelitos, de raigambre popular campesina, fueron muy comunes hasta bien entrado el siglo XX chileno. Domínguez, en otro poema posterior (Domínguez, 2000:39), recuerda a "la última llorona", Vicky Báez, la mujer experta en llorar en los "velorios de pobre / de angelitos sentados" (39), quien un día muere y con ella, la vieja tradición de los entierros campesinos.

En el marco de esta comunidad entendida como una gran hermandad llena de personajes populares y queridos como Vicky Báez, volvemos al poema anterior para dar cuenta que allí todo "es real y generoso / como el regazo de nuestra madre" (Domínguez, 1963:47). Señalamos, entonces, la presencia de este mundo como uno rodeado de cariño y generosidad maternal, donde todos sus habitantes son como el niño o la niña que se alimentan dulcemente del pecho de su madre, creciendo sana y vigorosamente. Una niñez cándida, armónica, que se expresa en ese niño que "vuelve más crecido de la escuela" (51) o en esos niños que sienten vergüenza cuando se les pide "cantar espontáneamente para las visitas / cuando son muchos y desconocidos los que llegan" (53). Una niñez que surge producto de una "vacilante alquimia" (59) y de los "embriones primitivos" (61) del amor humano, pero que sin embargo resulta de "pasto dulce" (72), que crece sin las grandes complejidades de la vida moderna. Se trata de una ligazón que hace que la gente del campo sea entendida como una sola gran familia sin hacer grandes distinciones de filiación, legitimidad o bastardía. Así, resulta 


\section{Claudio Guerrero}

natural que fueran estos habitantes de la comunidad los que "con las manos cuarteadas" se encargaron "de mudarme los pañales / cuando murió mi madre" (El sol mira para atrás. Domínguez, 1977:59). Una comunidad, insistimos, protectora de la infancia que viene a reparar, en un sentido, toda posible orfandad, todo posible huachismo.

Es por todo esto que resulta posible afirmar que uno de los grandes temas de la poesía de Delia Domínguez tiene que ver con la idea del nacimiento de un niño como un acto esperanzador y significativo. Esto se ve profundamente realizado en el poema "Comunidad de amor" del libro Contracanto (1968). Aquí, una vez más consideramos la primera infancia en el contexto de una "comunidad", de un espacio protegido, propicio para el crecimiento del bebé. El poema es breve y vale la pena considerarlo en toda su extensión:

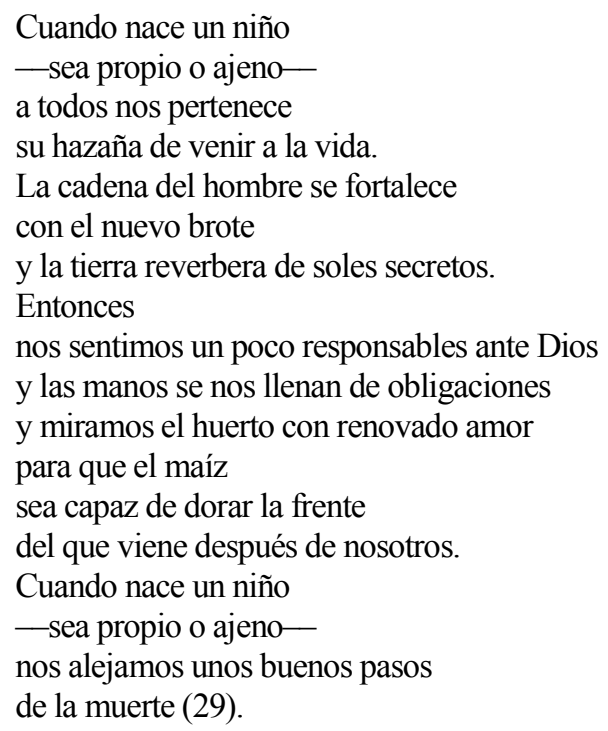

Como vemos, la hablante considera el nacimiento como una hazaña, una gesta heroica, que cumple una función de renovación del espíritu y de la especie, un poder revivir al adulto, sacarlo de su entorno agobiado de adultez y alejarlo de la muerte. Gracias al recién nacido, el adulto renueva su mirada y se siente partícipe de una "comunidad de amor" cuyo centro es el querer humano y su mayor regalo, la procreación: el niño, la niña, independientemente de la ausencia/presencia tanto de madre como de padre.

\section{MIRAR HACIA ATRÁS}

Como hemos podido apreciar, en esta poesía hay un constante anhelo por volver a un estado primigenio, casi al primer instante de vida, como una manera de recuperar el soplo vital, necesario y significativo para la existencia actual, en el marco 
de una comunidad de amor donde se encuentran la madre con la hija, los personajes queridos de la comarca, la naturaleza y los animales, en una perfecta sincronía amorosa y poética. En esta búsqueda, la infancia pareciera cumplir un rol reunificador, puesto que en ella se vierten todo lo mejor de la comunidad, todos los anhelos y todas las esperanzas por una vida mejor. Pero este trabajo es, esencialmente, una iniciativa personal del hablante que insistentemente "mira hacia atrás", en una regresión cada vez más aguda y más lejana en el tiempo: ya no alcanza solo con la niñez, los dientes de leche, el amamantamiento. Hay que llegar más lejos: al nacimiento, a la placenta, al embrión, en esta suerte de viaje a la semilla carpentieriano de la cual hablábamos en un comienzo.

Mirar hacia atrás es inscribirse en el marco de una herencia, una genealogía, "es interpretar las huellas y vestigios del pasado como una manera de responder a la pregunta sobre el yo y a la pregunta sobre el otro cuya memoria me es legada" (Saraceni, 20). Sin embargo, mirar hacia atrás es tener una idea del pasado como una temporalidad en proceso, un saber que nunca va a llegar al lugar del origen, porque ese lugar no se puede restituir. Por esto, la memoria y la escritura sobre infancia en esta poesía son el resultado de un desplazamiento que no intentan restituir el pasado, sino más bien aproximarse a él mediante recursos poéticos disímiles. Y uno de ellos es esta insistente búsqueda de volverse embrión. De esta manera, el presente adquiere un sentido nuevo.

Este singular tipo de viaje se puede apreciar en el poema "Canción de cuna" presente en libro El sol mira para atrás (1977), en donde la hablante ficcionaliza en primera persona su propio nacimiento, pero de un modo tal que lo de canción de cuna parece irónico, por las circunstancias trágicas en que su madre da a luz 5 . Ese día "estaba esperando nacer" (29), pero no solo eso, estaba esperando, además, que alguien le preparara "un lugar en la vida / después del pecho de mi madre / y estancarme la sangre del ombligo" (29). Alguien que le ayudara a crecer: un padre, una madre, una familia. Pero ese día, todo iba a estar signado por la dificultad de nacer. Ese día, "se me paró la música en la boca del estómago" (30) y todo se hizo repentino, porque nadie iba a llegar para salvar a su madre en medio de un pueblo andino donde no conocían a nadie. Su destino parecía ser el de no nacer: "tendrías que morirte sin remedio / y yo encerrada en ti / apenas un temblor de áspera selva" (30). Y entretanto la visión del oscuro útero, del saco protegido, "la nostalgia en el ropón oscuro / la dulce intimidad de tus caderas" (30), ese dulce estar adentro, pero sin poder salir hasta que de pronto "el tiempo se nos vino encima (...) y te sentí apretar los dientes / cuando silbó en la sombra el navajazo" (30), fijando todo el dolor en la figura de la madre y en el recién nacido las marcas de su venida al mundo: "Y este hueco en la almohada / la cálida humedad de tu cintura / y otros signos / quedaron para mi nacimiento" (30), como terrible canción de cuna, como signo de una primera

\footnotetext{
${ }^{5}$ Este poema posteriormente sería republicado, precisamente, bajo el título de "Canción de cuna al revés" (Domínguez, 1995:66-67), lo que remarca esta apreciación.
} 


\section{Claudio Guerrero}

muerte, que rompe con el idilio cálido y protegido por la construcción de la placenta durante el periodo de embarazo.

PONER LA CHAPA

En el poema "Se pasa llave a la chapa de 1931" (recordemos: fecha de nacimiento de la autora), incluido en Huevos revueltos (2000) la hablante señala: "Y comienza la marcha de regreso. / La mudez necesaria en su rigor interno / es lo que más importa, solas / caen las máscaras" (65). La mudez de la infancia es lo que más importa, el tiempo donde es posible encontrar una definición hasta que sea la hora de "pasar cerrojo a las chapas de infancia / (Un fierro martillado de los mil novecientos)" (65), cerrarla, darle un fin, un término con sentido, ese cuarto oscuro sin llave, ese viejo fierro aportillado de un siglo. Como si allí se encontraran las verdaderas definiciones, como si a partir de allí fuera posible entenderse en la adultez. Pasar cerrojo a la infancia significa, entonces, moldear un sentido. Una significación para su comprensión. Así, en definitiva, se intenta trazar un mapa de infancia en toda su poesía, una cartografía del niño y de la niña que viven solos, desnudos, ante el mundo. Una cartografía del huérfano y de su sombra, el huacho/a. Como señala en el poema llamado precisamente "Mapa de infancia", presente en Clavo de olor (2004), que transcribimos íntegramente:

Nadie sabe cuándo empieza el regreso.

Los viajes son cuerpos desvanecidos

en las camisetas de la niebla.

La leyenda del niño

es una alquimia de luz sobre los vidrios.

Su monólogo oscila entre el valor y el miedo

cuando aúllan los perros en creciente

acompañando la oración de un muerto.

Su mapa es la memoria no fechada en los

libros.

Un trazado invisible

siempre marca la vuelta hacia el ombligo

de una mujer que huele a leche ácida desde

la fundación del tiempo (45-46).

Este poema no solo nos recuerda la idea de la mente de un niño como un gran mapa, tal como lo describe James Matthew Barrie en Peter Pan y Wendy (1911), 6 sino que especialmente como un mapa de límites borrosos que, como señala Honeyman (2005:51-53), ha sido utilizado tradicionalmente por las literaturas que hablan de

\footnotetext{
${ }^{6}$ El lugar que se representa en esta obra es el País de Nunca Jamás, el cual es el equivalente al mapa de la mente de un niño. Este espacio es descrito como "siempre más o menos una isla" (11), lejana, indefinible, llena de personajes míticos.
} 
infancia ante el deseo de dar una forma delimitable a este espacio (la infancia) que de por sí es inaccesible. Es curioso constatar que en este poema la infancia esté descrita a base de una memoria sin fecha (tiempo), en un trazado invisible (lugar), reafirmando la idea de su carácter fantasmal y elusivo. Pero no solo eso. También reafirma lo que hemos venido diciendo desde un principio: que esta es una poesía escrita con la tira del ombligo en la mano y con los ojos mirando hacia atrás en busca de una fundación de sentido poético, maternal y comunitario, en busca de una inscripción de una herencia en una genealogía biomaterna marcada, inauguralmente, por la orfandad.

Este poema, en conclusión, bien puede ser una síntesis del significado que esta autora le atribuye a la infancia dentro de su poesía. En primer lugar, que esta es un regreso, es un viaje que se hace desde la adultez y que no tiene fecha determinada. Un día simplemente comienza. Ese día se empieza a ser adulto. En segundo lugar, que ese regreso hacia la infancia es nebuloso, incierto y agotador, semejante a un cuerpo desvanecido que hay que revivir. En tercer lugar, que el niño, la infancia, es una leyenda, un relato. Una historia luminosa, reflectante, mágica y secreta como la alquimia. Es decir, es la historia de la búsqueda de una cierta pureza imposible. En cuarto lugar, que el niño vive en soledad, como el huérfano signado por la muerte o como el huacho signado por la ausencia, ambos abandonados existencialmente en un mundo despatriarcalizado, pero sustituido por la matriarcalidad. Su infancia es un largo y oscilante monólogo con la muerte, entre la aventura y el miedo, entre el vivir y el morir. En quinto lugar, que la infancia es como un mapa sin fechas ni registros claros. Es una memoria que se rescata. Es un libro abierto y un espacio cerrado a la vez. Y, en sexto lugar, que en ese mapa están las huellas de un trazado invisible que siempre marca la vuelta hacia el origen, la vuelta hacia el ombligo, hacia el nacimiento, hacia el útero, hacia el embrión. Una forma de mirar hacia atrás.

En ese mapa surgen, entonces, como huellas, los registros de una infancia cuyos detalles son inciertos, fragmentados, imbricados como hilachas, pero que al reconstituirse en tanto relato forman una historia y una representación: la de una niña con olor a leche ácida, una niña con reflujos de infancia, destetada a destiempo, nacida "de avenas huachas" (48), cuya historia ha sido escrita con "lápiz de leche" (49), ese lápiz de piedra blanca "antiguamente usado por escolares para escribir en sus pizarras del colegio" (49). Es decir, la historia escrita por una voz vista a sí misma como niña y como niña sola. $\mathrm{O}$, mejor dicho, de una adulta que necesita que el espejo en donde se refleja le proyecte una imagen ahuachada de su infancia huérfana, despedazada, de leche cortada.

Pontificia Universidad Católica de Valparaíso* Instituto de Literatura y Ciencias del lenguaje Avda. El Bosque 1290, Viña del Mar (CHILE) claudio.guerrero@ucv.cl 


\section{OBRAS CITADAS}

Campaña, Antonio. "Poesía de Delia Domínguez". Atenea 446. (1982):161-164. Carpentier, Alejo. Viaje a la semilla y otros relatos. Santiago: Nascimento, 1971. Cuneo, Ana María. "Delia Domínguez: de la angustia a la esperanza". Mapocho 48. (2000):39-51.

----- "Delia Domínguez: experiencia y canto". Revista Chilena de Literatura 64. (2004):5-27.

Domínguez, Delia. La tierra nace al canto. Santiago: Ediciones del Grupo Fuego de la Poesía, 1958.

Obertura siglo XX. Santiago: Del Pacífico, 1961.

-----Parlamentos del hombre claro. Del amor humano. Santiago: Universitaria, 1963.

----- Contracanto. Santiago: Nascimento, 1968.

------ El sol mira para atrás. Santiago: Lord Cochrane, 1977.

------ La gallina castellana y otros huevos. Santiago: Tacamó Ediciones, 1995.

----- Huevos revueltos. Santiago: Tacamó Ediciones, 2000.

----- Clavo de olor. Barcelona: DeBolsillo, 2004.

Guerra, Lucía. La mujer fragmentada: historias de un signo. Bogotá: Casa de las Américas, 1994.

Honeyman, Susan. Elusive childhood. Impossible representations in modern fiction. Columbus: The Ohio State University Press, 2005.

Irigaray, Luce. Yo, tú, nosotras. Madrid: Cátedra, 1992.

Lenz, Rodolfo. Diccionario etimolójico de las voces chilenas derivadas de lenguas indijenas americanas. Santiago: Cervantes, 1904.

Mansilla, Sergio. "Poesía en el Paralelo 40 Sur. Memoria mestiza y territorio en la poesía de Delia Domínguez y Jaime Huenún". Inti 69-70. (2009):43-62.

------ "Delia Domínguez: palabras para la misa del universo", en Alpha 20. (2004):53-68.

Mistral, Gabriela. Ternura. 1924. Santiago: Universitaria, 1989.

Montecino, Sonia. Madres y huachos. Alegorías del mestizaje chileno. Santiago: Catalonia, 2007, cuarta edición ampliada y actualizada.

Salazar, Gabriel. Ser un niño huacho en la historia de Chile (siglo XIX). 1990. Santiago: LOM, 2007.

Saraceni, Gina. Escribir hacia atrás. Buenos Aires: Beatriz Viterbo editora, 2008.

Subercaseux, Benjamín. Daniel (niño de lluvia). Santiago: Ercilla, 1942. 